\title{
Statin-associated side effects in patients attending a lipid clinic: evidence from a 6-year study
}

Fotios Barkas, Petros Adamidis, Amalia-Despoina Koutsogianni, George Liamis, Evangelos Liberopoulos

Department of Internal Medicine, Faculty of Medicine, School of Health Sciences, University of Ioannina, Ioannina, Greece

Submitted: 28 July 2021

Accepted: 4 October 2021

Arch Med Sci Atheroscler Dis 2021; 6: e182-e187

DOI: https://doi.org/10.5114/amsad.2021.111313

Copyright (c) 2021 Termedia \& Banach

\section{Abstract}

Introduction: There is conflicting evidence regarding the actual incidence of statin-associated side effects in clinical practice. We aimed to record the incidence of statin-associated side effects in the setting of a lipid clinic. We focused on clinically relevant liver enzyme increase and statin-associated muscle symptoms (SAMS).

Material and methods: This was a retrospective study including adult patients with dyslipidemia followed up for $\geq 3$ years in a university hospital lipid clinic in Greece. We recorded the incidence of clinically relevant liver enzyme increase (>3 $3 \times$ upper limit of normal (ULN) on 2 occasions) and SAMS (muscle crumps, creatine kinase (CK) increase $>10 \times U L N$ and rhabdomyolysis) during follow-up.

Results: Among study participants $(n=1,334), 3.1 \%$ and $2.8 \%$ presented with clinically relevant liver enzyme increase and SAMS at least once during a median follow-up of 6 years $(4-10)$. Only $11 \%(n=5)$ of subjects with a clinically relevant liver enzyme increase and $6 \%(n=2)$ of those with SAMS did not tolerate any statin at any dose. Most subjects with a history of a clinically relevant liver enzyme increase or SAMS were eventually treated with a moderate- or high-intensity statin ( $76 \%$ and $80 \%$, respectively) or with combination treatment of a statin plus another lipid-lowering drug ( $15 \%$ and $36 \%$, respectively). No risk factors for these statin-associated side effects were identified.

Conclusions: The incidence of statin-associated side effects is low in the setting of a lipid clinic. The vast majority of these individuals were still able to tolerate statin treatment.

Key words: side effect, liver, muscle, statin.

\author{
Corresponding author: \\ Dr Evangelos Liberopoulos \\ Faculty of Medicine \\ School of Health Sciences \\ University of loannina \\ 45110 loannina, Greece \\ Phone: +302651099265 , \\ +302651007502, \\ $+306972022747$ \\ Fax: +302651007016 \\ E-mail: vaglimp@yahoo.com, \\ elibero@uoi.gr
}

\section{Introduction}

Statins are the most commonly prescribed drugs nowadays and remain the cornerstone therapy in cardiovascular (CV) prevention [1]. Well-documented statin-associated side effects include new-onset diabetes, statin-associated muscle symptoms (SAMS), and liver enzyme increase [1-3]. SAMS and clinically relevant liver enzyme increase are the major causes of partial or total statin intolerance [2-4]. The actual frequency of statin-associated side effects is uncertain and differs between randomized controlled trials (RCTs) and observational studies $[2,3]$. Although more than $90 \%$ of patients with SAMS could eventually be treated with statins, the rate of treatment withdrawal remains high 
[5], and is associated with a large increase in cardiovascular morbidity and mortality $[6,7]$. In this regard, 2 randomized, double blind, placebo controlled n-of-1 trials, the Self-Assessment Method for Statin Side-effects Or Nocebo (SAMSON) and Statin Web-based Investigation of Side Effects (StatinWISE) trials, recently demonstrated that a considerable proportion of subjects with SAMS tolerated the re-initiation of statin therapy $[8,9]$.

In this context, we aimed to identify the incidence of statin-associated side effects and 'true' statin intolerance in the setting of a lipid clinic. In the present work, we mainly focused on clinically relevant liver enzyme increase and SAMS.

\section{Material and methods}

This was a retrospective study including 1,334 consecutive adult patients with dyslipidemia who attended the Outpatient Lipid Clinic of the University Hospital of Ioannina in Greece for $\geq 3$ years (from 1999 to 2015) [10-13]. Our study protocol was approved by the Local Institutional Ethics Committee and informed consent was obtained from each patient.

Study details have been previously published [10-13]. All study participants were of Caucasian origin. A complete assessment of clinical and laboratory profile was performed at regular visits during follow-up. Patient demographic and clinical characteristics included: i) sex, ii) age, iii) smoking, iv) follow-up duration, v) concomitant diseases, with a particular emphasis on atherosclerotic cardiovascular disease (ASCVD) and CV risk factors, vi) body mass index (BMI) and waist, and vii) blood pressure. Laboratory data included: i) fasting plasma glucose (FPG), ii) a complete lipid profile, including total cholesterol (TC), triglycerides (TG), high-density lipoprotein cholesterol (HDL-C) and low-density lipoprotein cholesterol (LDL-C), iii) creatinine, iv) creatine kinase (CK) and v) liver enzymes, including aspartate transaminase (AST), alanine transaminase (ALT), $\gamma$-glutamyl transpeptidase $(\gamma-G T)$, alkaline phosphatase (ALP), and total and direct bilirubin (TBIL and DBIL).

Concomitant therapy was additionally recorded, with a particular emphasis on lipid-lowering drugs. The intensity of statin therapy was classified as 'high', 'moderate' and 'low' based on the average expected LDL-C lowering of $\geq 50,30-50$ and $<30 \%$, respectively [1].

Clinically relevant liver enzyme increase was defined as persistent elevations in hepatic aminotransferases (AST, ALT) by $>3 \times$ upper limit of normal (ULN) (at least on 2 occasions) [2]. SAMS included: i) myalgias (i.e. muscle pain and/or muscle crumps), ii) marked elevation of creatine kinase (CK) (> $10 \times$ ULN), and iii) rhabdomyolysis (CK increase $>40 \times$ ULN associated with renal impair- ment and/or myoglobinuria) [3]. The definition of statin intolerance was based on the inability to tolerate at least 2 different statins with one statin at the lowest daily dose $[3,4]$. Statin intolerance may be total if no statin can be tolerated or partial if some statin can be eventually given (e.g., intermittent dosing).

The study was conducted according to the guidelines of the Declaration of Helsinki and approved by the Ethics Committee of the University General Hospital of Ioannina, Greece (220/23-05-2012).

\section{Statistical analysis}

Continuous variables were tested for normality by the Kolmogorov-Smirnov test and logarithmic transformations were performed if necessary. Data are presented as mean \pm standard deviation (SD) and median (interquartile range (IQR)) for parametric and non-parametric data, respectively. For categorical values, frequency counts and percentages were applied. The $\chi^{2}$ test was performed for interactions between categorical values. The independent sample $t$-test (parametric and non-parametric) was used for the comparison of continuous numeric values between 2 groups. One-way analysis of variance (one-way ANOVA) was performed to assess the difference of the variables of interest between $\geq 2$ groups. Univariate binary logistic regression analysis was performed to investigate the association of a factor with the investigated outcomes of interest. Multivariate logistic regression analysis was conducted using the variables that were statistically significant in the univariate analyses (backward conditional method was used). Associations with the outcomes of interest are expressed as odds ratios (OR) with accompanying $95 \% \mathrm{Cl}$. Two-tailed significance was defined as $p<0.05$. Analyses were performed with the SPSS v21.0 software (SPSS IBM Corporation, Armonk, New York, USA).

\section{Results}

A total of 1,334 subjects were included in the present study. Of those, $79 \%(n=1,058)$ were statin-naivve upon inclusion and were subsequently prescribed a statin. During a median follow-up of 6 years (4-10), $3.1 \%$ and $2.8 \%$ of participants presented with clinically relevant liver enzyme increase and SAMS at least once, respectively. There was no difference between statin-naïve patients and those already on statin: $3.2 \%$ vs. $2.7 \%, p=$ NS, for the incidence of relevant liver enzyme increase, and $3.1 \%$ vs. $3.0 \%, p=N S$, for the incidence of SAMS.

Among those with SAMS, $2.0 \%$ of subjects reported myalgias and $1.1 \%$ had increased CK > $10 \times$ ULN. No significant differences were noted between groups apart from the lower prescrip- 
Table I. Clinical and laboratory data of study participants at last visit

\begin{tabular}{|c|c|c|c|c|}
\hline Parameter & $\begin{array}{l}\text { Total popula- } \\
\text { tion }\end{array}$ & $\begin{array}{l}\text { Subjects with } \\
\text { no adverse } \\
\text { effects }\end{array}$ & $\begin{array}{l}\text { Subjects with } \\
\text { clinically rele- } \\
\text { vant liver en- } \\
\text { zyme increase }\end{array}$ & $\begin{array}{l}\text { Subjects with } \\
\text { SAMS }\end{array}$ \\
\hline N & 1,334 & 1,257 & 41 & 37 \\
\hline Sex (male) (\%) & 46 & 46 & 49 & 34 \\
\hline Age [years] & $64(55-73)$ & $64(55-72)$ & $63(54-74)$ & $66(58-78)$ \\
\hline Follow-up [years] & $6(4-10)$ & $6(4-10)$ & $5(4-9)$ & $5(3-11)$ \\
\hline Atherosclerotic cardiovascular disease (\%) & 22 & 22 & 21 & 20 \\
\hline Familial hypercholesterolemia (\%) & 12 & 12 & 4 & 13 \\
\hline Type 2 diabetes (\%) & 19 & 19 & 8 & 17 \\
\hline Chronic kidney disease (\%) & 14 & 14 & 13 & 18 \\
\hline Hypertension (\%) & 70 & 71 & 72 & 66 \\
\hline Metabolic syndrome (\%) & 45 & 46 & 40 & 36 \\
\hline Hypothyroidism (\%) & 9 & 9 & 18 & 6 \\
\hline Smoking (\%) & 17 & 17 & 8 & 12 \\
\hline Body mass index $\left[\mathrm{kg} / \mathrm{m}^{2}\right]$ & $28.3(25.6-31.2)$ & $28.3(25.8-31.1)$ & $27.9(26.2-31.2)$ & $27.0(24.9-30.8)$ \\
\hline Waist [cm] & $100(91-107)$ & $100(91-107)$ & $101(93-110)$ & $95(89-102)$ \\
\hline Systolic blood pressure [mm Hg] & $129(120-136)$ & $129(120-136)$ & $128(122-135)$ & $130(121-138)$ \\
\hline Diastolic blood pressure [mm Hg] & $78(72-84)$ & $78(72-84)$ & $77(70-83)$ & $77(72-83)$ \\
\hline Fasting plasma glucose [mg/dl] & $98(95-106)$ & $98(90-109)$ & $96(89-107)$ & 97 (92-109) \\
\hline $\begin{array}{l}\text { Estimated glomerular filtration rate } \\
{\left[\mathrm{ml} / \mathrm{min} / 1.73 \mathrm{~m}^{2}\right]}\end{array}$ & $75(64-83)$ & $74(64-83)$ & $77(61-87)$ & $70(60-80)$ \\
\hline Total cholesterol [mg/dl] & $174(151-198)$ & $174(151-198)$ & $170(157-197)$ & $174(148-206)$ \\
\hline Triglycerides [mg/dl] & $109(82-149)$ & $109(83-148)$ & $125(90-162)$ & $98(73-146)$ \\
\hline $\begin{array}{l}\text { High-density lipoprotein cholesterol } \\
{[\mathrm{mg} / \mathrm{dl}]}\end{array}$ & $53(45-61)$ & $53(44-61)$ & $50(45-59)$ & $53(49-63)$ \\
\hline $\begin{array}{l}\text { Low-density lipoprotein cholesterol } \\
{[\mathrm{mg} / \mathrm{dl}]}\end{array}$ & $96(78-115)$ & $95(78-115)$ & $96(84-113)$ & $96(77-117)$ \\
\hline Thyroid stimulating hormone [mIU/I] & $1.23(0.80-1.88)$ & $1.23(0.79-1.85)$ & $1.41(0.97-1.89)$ & $1.34(1.08-1.85)$ \\
\hline \multicolumn{5}{|l|}{ Concomitant treatment } \\
\hline Lipid lowering therapy (\%) & 95 & 95 & 90 & 100 \\
\hline Statin (\%) & 92 & 92 & $89^{*}$ & 94 \\
\hline \multicolumn{5}{|l|}{ Type of statin, \% (median dose): } \\
\hline Atorvastatin & $40(20 \mathrm{mg})$ & $40(20 \mathrm{mg})$ & $44(20 \mathrm{mg})$ & $50(20 \mathrm{mg})$ \\
\hline Rosuvastatin & $29(20 \mathrm{mg})$ & $29(20 \mathrm{mg})$ & $31(20 \mathrm{mg})$ & $26(10 \mathrm{mg})$ \\
\hline Simvastatin & 19 (40 mg) & $20(40 \mathrm{mg})$ & $10(40 \mathrm{mg})$ & $12(40 \mathrm{mg})$ \\
\hline Fluvastatin & $3(80 \mathrm{mg})$ & $3(80 \mathrm{mg})$ & $5(80 \mathrm{mg})$ & $9(80 \mathrm{mg})$ \\
\hline Pravastatin & $1(40 \mathrm{mg})$ & $1(40 \mathrm{mg})$ & 0 & 0 \\
\hline \multicolumn{5}{|l|}{ Intensity of statin therapy (\%): } \\
\hline High-intensity & 33 & 33 & 29 & 20 \\
\hline Moderate-intensity & 50 & 50 & 47 & 60 \\
\hline Low-intensity & 10 & 9 & 13 & 14 \\
\hline Ezetimibe (\%) & 24 & 24 & 13 & 34 \\
\hline Colesevelam (\%) & 1 & 1 & 3 & 3 \\
\hline Fibrates (\%) & 6 & 6 & 8 & 3 \\
\hline Statin combination therapy (\%) & 29 & 30 & 15 & 36 \\
\hline Omega-3 fatty acids (\%) & 4 & 4 & 3 & 3 \\
\hline
\end{tabular}

${ }^{*} p<0.05$ for the comparison with subjects with no adverse effects. SAMS - statin-associated muscle symptoms, ULN - upper limit of normal. 
tion rates of high-intensity statins in patients with a history of relevant liver enzyme increase or SAMS (Table I).

Only $11 \%(n=5)$ of subjects with a history of relevant liver enzyme increase and $6 \%(n=2)$ of those with SAMS did not tolerate any statin at any dose (total statin intolerance).

Most subjects with a history of relevant liver enzyme increase or SAMS were eventually treated with a moderate- or high-intensity statin $(76 \%$ and $80 \%$, respectively for the 2 groups) or with combination of a statin with another lipid-lowering drug (15\% and $36 \%$, respectively, Table I).

The statin-treated subjects with SAMS had higher CK levels compared with subjects with a history of relevant liver enzyme increase or no side effects (Table II). No risk factors for these statin-related side effects were identified (Table III).

\section{Discussion}

The present study shows that the incidence of statin-associated clinically relevant liver enzyme increase and SAMS is low in the setting of a lipid clinic. Most subjects with a history of relevant liver enzyme increase or SAMS were eventually treated with a statin with or without a second lipid-lowering drug.
Although RCTs have provided reassurance regarding statin safety, these have included specific patient populations fulfilling certain inclusion and exclusion criteria and treated for a relatively short duration. In this context, the incidence of statin-associated side effects may be higher in unselected populations treated in clinical practice. Relevant liver enzyme increase and SAMS are the most frequent statin-associated side effects [2-4]. Although a variety of risk factors have already been established $[3,14]$, we could not find any significant predictors for statin-associated side effects in this study. This may be partially explained by its small sample size and the low actual incidence of statin-associated side effects.

Although true statin-induced hepatotoxicity is extremely rare (1.2 per 100,000 patients) [15], liver enzymes might increase in clinical practice $[2,4]$. Indeed, asymptomatic elevation of liver transaminases occurs in $0.5-2.0 \%$ of patients on any statin therapy, usually within 3 months of treatment initiation [2, 4]. These elevations have a clear dose-response relationship, but are transient and usually normalized with ongoing therapy [16]. Clinically relevant liver enzyme increase is rare. An analysis of 49 RCTs $(n=14,000)$ demonstrated persistent elevations in hepatic transaminases ( $>3 \times U L N)$ in $0.1 \%, 0.6 \%$, and $0.2 \%$ of pa-

Table II. Safety profile of statin-treated subjects at last visit

\begin{tabular}{|lcccc|}
\hline Parameter & Total population & $\begin{array}{c}\text { Subjects without } \\
\text { side effects }\end{array}$ & $\begin{array}{c}\text { Subjects with } \\
\text { relevant liver } \\
\text { enzyme increase }\end{array}$ & $\begin{array}{c}\text { Subjects with } \\
\text { SAMS }\end{array}$ \\
\hline Aspartate aminotransferase [U/l] & $23(20-27)$ & $23(20-27)$ & $25(20-28)$ & $24(19-27)$ \\
\hline Alanine aminotransferase [U/l] & $22(17-29)$ & $22(17-29)$ & $23(17-29)$ & $23(16-27)$ \\
\hline$\gamma$-glutamyltranspeptidase [U/l] & $18(13-27)$ & $18(13-27)$ & $17(13-23)$ & $19(12-28)$ \\
\hline Alkaline phosphatase [U/l] & $58(48-73)$ & $58(48-73)$ & $60(47-75)$ & $58(51-68)$ \\
\hline Creatine kinase $[\mathrm{U} / \mathrm{l}]$ & $106(78-156)$ & $104(77-156)^{*}$ & $121(79-150)^{*}$ & $134(108-211)$ \\
\hline Total bilirubin $[\mathrm{mg} / \mathrm{dl}]$ & $0.7(0.6-0.9)$ & $0.7(0.58-0.9)$ & $0.8(0.7-0.9)$ & $0.7(0.4-0.9)$ \\
\hline Direct bilirubin $[\mathrm{mg} / \mathrm{dl}]$ & $0.13(0.10-0.18)$ & $0.13(0.10-0.18)$ & $0.16(0.12-0.17)$ & $0.14(0.09-0.17)$ \\
\hline
\end{tabular}

${ }^{*} P<0.05$ for the comparison with the subjects with SAMS. SAMS - statin-associated muscle symptoms.

Table III. Risk factors of relevant liver enzyme increase or statin-associated muscle symptoms

\begin{tabular}{|lc|}
\hline Parameter & Odds ratio (95\% confidence interval) \\
\hline Sex (male) & $0.82(0.51-1.32)$ \\
\hline Age, per 1-year increase & $1.007(0.998-1.027)$ \\
\hline Type 2 diabetes & $0.59(0.29-1.21)$ \\
\hline Chronic kidney disease & $1.17(0.55-2.51)$ \\
\hline Hypothyroidism & $1.40(0.68-2.89)$ \\
\hline Heavy drinkers & $0.76(0.46-1.25)$ \\
\hline Body mass index, per 1-kg/m² increase & 1.00 \\
\hline Waist, per 1 -cm increase & $1.00(0.95-1.05)$ \\
\hline Estimated glomerular filtration rate, per $1-\mathrm{ml} / \mathrm{min} / 1.73 \mathrm{~m}^{2}$ increase & $0.99(0.98-1.01)$ \\
\hline Thyroid stimulating hormone, per $1-\mathrm{m} / \mathrm{U} / \mathrm{l}$ increase & $0.95(0.73-1.22)$ \\
\hline
\end{tabular}


tients treated with atorvastatin $10 \mathrm{mg}, 80 \mathrm{mg}$, and placebo, respectively. The incidence of relevant liver enzyme increase noted in this study is higher than previously described in statin trials [17]. This could be attributed to its longer follow-up compared with statin trials, and the enrollment of an unselected population, including elderly subjects with many comorbidities.

SAMS are the most common side effects [3]. Statins may decrease mitochondrial function, attenuate energy production, and alter muscle protein degradation, thereby resulting in muscle symptoms [3]. Statin-associated marked CK elevation ( $>10 \times$ ULN) is a rare but serious side effect affecting 1 : 1,000-10,000 statin-treated patients [3]. Rhabdomyolysis is even less frequent $(0.01 \%)$ [4]. However, muscle symptoms, such as pain, stiffness, tenderness or cramps, are more common and are usually associated with normal or slightly elevated CK [3]. In contrast to RCTs, patient registries and post-market reports indicate that 7-29\% of patients report SAMS [1-3]. Herein, we report a much lower SAMS frequency (2.8\%). A possible explanation is that this study was conducted in the setting of a lipid clinic. Specialized physicians could carefully assess related symptoms, and thus reported a lower incidence of SAMS. Also, compliance with treatment may be better in this setting. The Effects of Statins on Muscle Performance (STOMP) trial, the first randomized, double-blinded, placebo-controlled trial investigating the effect of atorvastatin $80 \mathrm{mg}$ on SAMS in 420 statin-naïve subjects, showed a higher prevalence of myalgias in statin-treated subjects compared with placebo (9.4\% vs. $4.6 \%, p=0.054)$ [18]. An analysis from the Anglo-Scandinavian Cardiac Outcomes Trial-Lipid-Lowering Arm (ASCOT-LLA) showed that the reporting annual rate of muscle adverse events did not differ between atorvastatin and placebo (2.03\% vs. $2.00 \%, p>0.05)$ in the blinded phase, but was higher among statin users than non-users in the non-blinded phase (1.26\% vs. $1.00 \%, p=0.006)$ [19]. Likewise, the rates of treatment withdrawal due to SAMS in the ODYSSEY ALTERNATIVE trial, which included 361 statin intolerant patients, were $16 \%$ in the alirocumab group, $20 \%$ in the ezetimibe group, and $22 \%$ in the atorvastatin group [20]. In the double-blind phase, 'statin-intolerant' patients withdrew treatment at similar rates regardless of treatment group allocation, whereas most patients could tolerate atorvastatin [20]. GAUSS-3 showed that $42.6 \%$ of 'statin-intolerant' patients reported intolerable SAMS with atorvastatin but not with placebo, whereas $26.5 \%$ of patients reported SAMS with placebo but not with atorvastatin [21]. This actually meant that true SAMS were seen in 4 out of 10 patients previously characterized as 'statin intolerant' [21]. Therefore, it seems that a large proportion of statin-associated effects may be attributed to the 'nocebo' effect.

According to a double-blind, three-group, n-of- 1 trial, the SAMSON study, $50-57 \%$ of patients who had previously discontinued statins due to side effects $(n=60)$ were able to resume long-term statin therapy [8]. In the same context, the StatinWISE study, a series of n-of- 1 trials $(n=200)$, demonstrated similar rates of intolerable muscle symptoms during a statin and placebo period ( $9 \%$ vs. $7 \%$ ), whereas two thirds of those completing the trial successfully initiated long-term statin therapy [9]. In line with these trials, the vast majority $(91 \%)$ of our study participants with previous statin-associate side effects were able to tolerate statin therapy.

The retrospective design is the major limitation of this study. No specific protocol regarding the report of side effects and statin dechallenge/rechallenge existed. The lack of data on comorbidities predisposing to increased risk for musculoskeletal symptoms or dedicated questionnaires for SAMS could have influenced our results.

On the other hand, this study had a long follow-up of 6 years in a real-world outpatient lipid clinic. Our results showing a low incidence of 'complete statin intolerance' underline the importance of careful assessment of statin-associated symptoms. Physicians should persist in the continuation or re-initiation of statin therapy in such patients and ensure best adherence to treatment.

In conclusion, the present study conducted in the setting of a lipid clinic with a long follow-up confirms that the incidence of clinically relevant liver enzyme increase and SAMS is low in clinical practice. Most patients can be eventually treated with a statin even if reporting statin-associated side effects.

\section{Conflict of interest}

Dr F. Barkas reports honoraria, grants and non-financial support from AMGEN, PFIZER, NOVO NORDISK, and VIATRIS, outside the submitted work.

Dr P. Adamidis and A.D. Koutsogianni declare no conflict of interest.

Dr. G. Liamis reports honoraria, grants and non-financial support from ANGELINI, BAYER, MENARINI, and SANOFI, outside the submitted work.

Dr. E. Liberopoulos reports personal fees from SANOFI, personal fees and non-financial support from AMGEN, personal fees from SERVIER, personal fees from BOEHRINGER-INGELHEIM, personal fees and non-financial support from ASTRA-ZENECA, personal fees from MSD, personal fees from LILLY, personal fees and non-financial support from BAYER, personal fees from NOVARTIS, and personal fees from CHIESI. 


\section{References}

1. Mach F, Baigent C, Catapano AL, et al. 2019 ESC/EAS Guidelines for the management of dyslipidaemias: lipid modification to reduce cardiovascular risk. Eur Heart J 2020; 41: 111-88.

2. Mach F, Ray KK, Wiklund O, et al. Adverse effects of statin therapy: perception vs. the evidence - focus on glucose homeostasis, cognitive, renal and hepatic function, haemorrhagic stroke and cataract. Eur Heart J 2018; 39: 2526-39.

3. Stroes ES, Thompson PD, Corsini A, et al. Statin-associated muscle symptoms: impact on statin therapy-European Atherosclerosis Society Consensus Panel Statement on Assessment, Aetiology and Management. Eur Heart J 2015; 36: 1012-22.

4. Banach M, Rizzo M, Toth PP, et al. Statin intolerance - an attempt at a unified definition. Position paper from an International Lipid Expert Panel. Expert Opin Drug Saf 2015; 14: 935-55.

5. Pedro-Botet J, Climent E, Benaiges D. Muscle and statins: from toxicity to the nocebo effect. Expert Opin Drug Saf 2019; 18: 573-9.

6. Serban MC, Colantonio LD, Manthripragada AD, et al. Statin intolerance and risk of coronary heart events and all-cause mortality following myocardial infarction. J Am Coll Cardiol 2017; 69: 1386-95.

7. Rodriguez F, Maron DJ, Knowles JW, Virani SS, Lin S, Heidenreich PA. Association of statin adherence with mortality in patients with atherosclerotic cardiovascular disease. JAMA Cardiol 2019; 4: 206-13.

8. Wood FA, Howard JP, Finegold JA, et al. N-of-1 trial of a statin, placebo, or no treatment to assess side effects. N Engl J Med 2020; 383: 2182-4.

9. Herrett E, Williamson E, Brack K, et al. Statin treatment and muscle symptoms: series of randomised, placebo controlled n-of-1 trials. BMJ 2021; 372: n135.

10. Barkas F, Elisaf M, Korantzopoulos P, Tsiara S, Liberopoulos E. The CHADS2 and CHA2DS2-VASc scores predict atrial fibrillation in dyslipidemic individuals: role of incorporating low high-density lipoprotein cholesterol levels. Int J Cardiol 2017; 241: 194-9.

11. Barkas F, Milionis H, Kostapanos MS, Mikhailidis DP, Elisaf M, Liberopoulos E. How effective are the ESC/EAS and 2013 ACC/AHA guidelines in treating dyslipidemia? Lessons from a lipid clinic. Curr Med Res Opin 2015; 31: 221-8.

12. Barkas F, Liberopoulos EN, Kostapanos MS, Liamis G, Tziallas D, Elisaf M. Lipid target achievement among patients with very high and high cardiovascular risk in a lipid clinic. Angiology 2015; 66: 346-53.

13. Barkas F, Elisaf M, Rizos EC, Liberopoulos E. Bridging the treatment gap in patients at 'extreme' cardiovascular risk: evidence from a lipid clinic. Atherosclerosis 2019; 281: 216-8

14. Mancini GB, Tashakkor AY, Baker S, et al. Diagnosis, prevention, and management of statin adverse effects and intolerance: Canadian Working Group Consensus update. Can J Cardiol 2013; 29: 1553-68.

15. Bjornsson E, Jacobsen El, Kalaitzakis E. Hepatotoxicity associated with statins: reports of idiosyncratic liver injury post-marketing. J Hepatol 2012; 56: 374-80.

16. Naci H, Brugts J, Ades T. Comparative tolerability and harms of individual statins: a study-level network meta-analysis of 246955 participants from 135 randomized, controlled trials. Circ Cardiovasc Qual Outcomes 2013; 6: 390-9.
17. Newman C, Tsai J, Szarek M, Luo D, Gibson E. Comparative safety of atorvastatin $80 \mathrm{mg}$ versus $10 \mathrm{mg}$ derived from analysis of 49 completed trials in 14,236 patients. Am J Cardiol 2006; 97: 61-7.

18. Parker BA, Capizzi JA, Grimaldi AS, et al. Effect of statins on skeletal muscle function. Circulation 2013; 127: 96-103.

19. Gupta A, Thompson D, Whitehouse A, et al. Adverse events associated with unblinded, but not with blinded, statin therapy in the Anglo-Scandinavian Cardiac Outcomes Trial-Lipid-Lowering Arm (ASCOT-LLA): a randomised double-blind placebo-controlled trial and its non-randomised non-blind extension phase. Lancet 2017; 389: 2473-81.

20. Moriarty PM, Thompson PD, Cannon CP, et al. Efficacy and safety of alirocumab vs ezetimibe in statin-intolerant patients, with a statin rechallenge arm: the ODYSSEY ALTERNATIVE randomized trial. I Clin Lipidol 2015; 9: 758-69.

21. Nissen SE, Stroes E, Dent-Acosta RE, et al. Efficacy and tolerability of evolocumab vs ezetimibe in patients with muscle-related statin intolerance: the GAUSS-3 randomized clinical trial. JAMA 2016; 315: 1580-90. 